\title{
Management of nursery practices for efficient ectomycorrhizal fungi application in the production of Quercus ilex
}

\author{
Rui S. Oliveira • Albina R. Franco • Miroslav Vosátka • \\ Paula M. L. Castro
}

\begin{abstract}
The application of ectomycorrhizal (ECM) fungi on forest nursery production is regarded as part of good management practice. However, before employing large scale inoculations in a nursery the interaction between ECM symbionts, growth substrate and fertilisation input should be studied to select the most suitable nursery practices for promoting plant growth and ECM colonisation. In this study, seedlings of Quercus ilex were inoculated with Paxillus involutus, Hebeloma mesophaeum or Cenococcum geophilum and grown in three different substrates commonly used in forest nurseries: peat-based compost, forest soil or composted pine bark. The effect of various fertilisation regimes was also studied. The choice of substrate had a significant effect on plant growth and ECM colonisation. The most appropriate combination of substrate and ECM fungus for $Q$. ilex growth and nutrition was peat and $H$. mesophaeum. Plants grown on a peat-based compost and inoculated with $H$. mesophaeum had a significantly greater biomass and leaf phosphorus concentration without fertilisation. Composted pine bark was found not to be suitable for growth or for mycorrhization. If the appropriate growth substrate is selected, it is possible to replace the use
\end{abstract}

The paper is part of the special issue 'The Potential of exploiting Mycorrhizal associations in semi arid regions'

R. S. Oliveira · A. R. Franco P. M. L. Castro $(\bowtie)$

$\mathrm{CBQF} /$ Escola Superior de Biotecnologia,

Universidade Católica Portuguesa,

Rua Dr. António Bernardino de Almeida,

4200-072 Porto, Portugal

e-mail: plcastro@esb.ucp.pt

M. Vosátka

Research Centre of Bioindication and Revitalisation, Institute of Botany, Academy of Sciences of the Czech Republic, 25243 Pruhonice, Czech Republic of chemical fertilisers by inoculation with selected ECM fungi. This results in a significant increase in plant development, and thus ECM fungi can be recommended as a more environmental friendly biotechnological approach to plant management in the nursery.

Keywords Forest nursery inoculation - Improved plant growth $\cdot$ Holm oak $\cdot$ Nursery substrate and fertilisation . Selected ectomycorrhizal fungi

\section{Introduction}

Holm oak (Quercus ilex L.) is an evergreen tree native to the Mediterranean region. It is one of the most abundant forest trees with an estimated 4.1 million ha of open woodland in the mid and western European countries bordering the Mediterranean. It is one of the main broadleaved tree species in Portugal, occupying $12 \%$ of the total forest area (Autoridade Florestal Nacional 2010).

The $Q$. ilex forests play a very important economic, ecological and socio-economic role providing wood, environmental protection, tourism, hunting and forage resources (Scarascia-Mugnozza et al. 2000).

Field transplantation of container-grown seedlings produced from seeds in nurseries is the most common method for establishing $Q$. ilex plantations.

The use of ectomycorrhizal (ECM) fungi in forest nursery provides the potential for increasing growth and vigour of seedlings under nursery conditions (Brundrett et al. 2005; Chen et al. 2006; Vosátka et al. 2008) and for improvement in quality and performance of outplanted seedlings (Domínguez et al. 2006; Quoreshi et al. 2008 Rivero et al. 2009). ECM fungi can improve plant survival and growth by stimulating the uptake of soil nutrients and 
water, and by increasing plant resistance against biotic (e.g. plant pathogens) and abiotic (e.g. presence of toxic elements) stresses (Chalot et al. 2002; Garbaye 2000; Hall 2002; Smith and Read 2008). Thus, the use of ECM fungi in forest nursery production may help to reduce the input of chemical fertilisers and pesticides, preventing the contamination of soil and water resources (Khasa et al. 2001). However, achieving the potential benefit from nursery inoculation is not always straightforward, and requires the selection of compatible and efficient ECM fungal isolates tuned to the specific target plant and growth conditions (Vosátka et al. 2008).

ECM fungi are known to form symbiotic associations with $Q$. ilex (Richard et al. 2005). However, with the exception of the Tuber spp. the effect of ECM inoculation on $Q$. ilex growth performance under different nursery conditions has been little studied. In particular, the type of growth substrate and the employed fertilisation regime can greatly influence both mycorrhization and plant growth (Liu et al. 2008; Vaario et al. 2009). The success of ECM inoculation and consequent improvement of the production of $Q$. ilex can be failed if the adopted nursery practices are not adequate. Furthermore, various ECM symbionts can have preferences not only to the host plant but also to the growth substrate and the fertiliser input (González-Ochoa et al. 2003; Rincón et al. 2007).

The aim of the present study was to improve the production of $Q$. ilex by selecting the most suitable growth substrate, fertilisation regime and ECM inoculant for efficient mycorrhization and plant growth promotion under nursery conditions.

\section{Materials and methods}

\subsection{Experimental design}

Seeds of Quercus ilex ssp. ballota (Desf.) Samp. collected in Avis, Portugal, were stratified at $4^{\circ} \mathrm{C}$ and surface sterilised in $2.5 \% \mathrm{NaOCl}$ for $5 \mathrm{~min}$. They were rinsed five times with sterile distilled water before sowing.

In Experiment 1, three growth substrates were tested: peat, forest soil and composted pine bark. The peat used was in the form of a peat-based compost, hereafter referred to a peat. The forest soil was collected in the uppermost $10 \mathrm{~cm}$ of a forest ecosystem in Amarante, Northern Portugal and it was sieved through a $4 \mathrm{~mm}$ mesh. The composted pine bark is a formulation made at the forest nurseries from grinded Pinus pinaster bark. In a forest nursery greenhouse, in Amarante, Northern Portugal, trays (390 mm long, $300 \mathrm{~mm}$ wide, $225 \mathrm{~mm}$ deep) with 20 cells $\left(800 \mathrm{~cm}^{3}\right.$ per cell) were filled with each of the growth substrates that were autoclaved three times $\left(121^{\circ} \mathrm{C}\right.$ for
$25 \mathrm{~min}$ ) on three consecutive days. The chemical and physical characteristics of the growth substrates after autoclaving are summarised in Table 1. For each substrate, there were four inoculation treatments: non-inoculated controls (C), and plants inoculated with Paxillus involutus (Batsch) Fr. (PI), Hebeloma mesophaeum (Pers.) Quél. (HM) or Cenococcum geophilum Fr. (CG). The ECM fungal isolates were isolated from a $Q$. ilex forest in Northern Portugal and were maintained by successive transfers in modified Melin Norkans agar (MMN, Marx 1969). These ECM fungal isolates were chosen for their compatibility with $Q$. ilex in previous laboratory studies (Oliveira et al. unpublished). Only one isolate of each ECM fungal species was used in these experiments. Inoculation was performed by injecting $6 \mathrm{ml}$ of mycelial suspensions to the substrate of each cell at the time of sowing. The suspension was prepared by cultivating in the ECM fungal isolates on liquid MMN for 3 weeks in a dark incubator at $25^{\circ} \mathrm{C}$. All treatments were replicated six times. In April, seeds with similar size were selected and two disinfected seeds were placed in each cell. All cells were covered with autoclaved vermiculite (Verlite, Vermiculita y Derivados S.L., Asturias, Spain). One month after planting seeds and inoculating the substrate, the plants were thinned to one seedling per cell and supplemented with $600 \mathrm{mg} /$ seedling of a NPK slow release fertiliser (release time 3 months) $\left(12 \% \mathrm{~N}, 12 \% \mathrm{P}_{2} \mathrm{O}_{5}, 17 \% \mathrm{~K}_{2} \mathrm{O}, 2 \% \mathrm{MgO}, 15 \% \mathrm{SO}_{3}, 0.02 \%\right.$ $\mathrm{B}, 0.1 \% \mathrm{Fe}, 0.01 \% \mathrm{Zn}$ ) (BASF, Germany). Seedlings were watered every 2 days and maintained under an average photoperiod of $8 \mathrm{~h}$. Greenhouse temperature varied between $5-41.0^{\circ} \mathrm{C}$ and relative humidity between $40-80 \%$. Trays of different treatments were periodically rotated to different bench positions to minimise differences due to their location in the greenhouse. The tested growth substrates

Table 1 Chemical and physical characteristics of the growth substrates

\begin{tabular}{lccc}
\hline & Peat & Forest soil & $\begin{array}{c}\text { Composted } \\
\text { pine bark }\end{array}$ \\
\hline $\mathrm{pH}(\mathrm{H} 2 \mathrm{O})$ & 6.47 & 6.20 & 7.30 \\
Conductivity $\left(\mathrm{mS} \mathrm{cm}^{-1}\right)$ & 14.39 & 0.20 & 4.76 \\
Organic matter (\%) & $>7$ & $>7$ & $>7$ \\
Total N (\%) & 0.74 & 0.41 & 1.28 \\
$\mathrm{~N}^{-\mathrm{NO}_{3}}{ }^{-}\left(\mathrm{mgkg}^{-1}\right)$ & 1636 & 10 & 111 \\
Olsen's P $\left(\mathrm{mgkg}^{-1}\right)$ & 788 & 140 & 98 \\
Total values $\left(\mathrm{mgkg}^{-1}\right)$ & & & \\
$\mathrm{K}$ & 10398 & 8798 & 1500 \\
$\mathrm{Ca}$ & 16400 & 4620 & 41800 \\
$\mathrm{Mg}$ & 31000 & 6600 & 2000 \\
$\mathrm{Na}$ & 4000 & 260 & 200 \\
\hline
\end{tabular}


Table 2 Two-way ANOVA significances and $F$ values of the parameters measured in Experiment 1, according to growth substrate and fungal inoculation

\begin{tabular}{llll}
\hline & $\begin{array}{l}\text { Shoot } \\
\text { height }(\mathrm{cm})\end{array}$ & $\begin{array}{l}\text { Total plant dry } \\
\text { weight }(\mathrm{g})\end{array}$ & $\begin{array}{l}\text { \% ECM } \\
\text { colonisation }\end{array}$ \\
\hline $\begin{array}{l}\text { Substrate (S) } \\
\begin{array}{l}\text { Fungal } \\
\text { inoculation (I) }\end{array}\end{array}$ & $F=23.2 * * *$ & $F=30.2 * * *$ & $F=25.8 * * *$ \\
S x I & $F=2.3 *$ & $F=1.6 \mathrm{~ns}$ & $F=0.9 \mathrm{~ns}$ \\
\hline
\end{tabular}

*, ***, significant effect at the level of $P<0.05$ and $P<0.001$, respectively; ns, non-significant effect; ECM, ectomycorrhizal

and fertilisation regime are those currently used in forest nurseries in Portugal.

Experiment 2 was initiated in the same month as Experiment 1, but in the following growing season. In Experiment 2, two fertilisation regimes were tested: 0 or $600 \mathrm{mg}$ of the above described fertiliser per seedling. The experimental design was the same as in Experiment 1, except for the fertilisation regime and the fact that only peat was used as growth substrate. This growth substrate was selected because it was found to be the most suitable for plant growth and ECM colonisation in Experiment 1.

\subsection{Plant and fungal parameters}

After 8 months of plant growth (one vegetation season), all seedlings were gently removed from the trays and transported to the laboratory for further analyses. The shoot height was measured and the root system was washed to remove adhered substrate. The percentage of ECM fungal colonisation was assessed using a stereomicroscope (SZ30, Olympus, Japan) according to Brundrett et al. (1996). The biomass was determined after drying the plant material at $70^{\circ} \mathrm{C}$ for $48 \mathrm{~h}$.

In Experiment 2, oven-dried leaves were finely ground and $0.2 \mathrm{~g}$ of material were digested according to Novozamsky et al. (1983). The digested samples were used to determine the total phosphorus $(\mathrm{P})$ and nitrogen $(\mathrm{N})$ concentrations in leaves by colorimetry (Unicam, Helios Gamma, Cambridge, UK) (Walinga et al. 1989).

\subsection{Statistical analysis}

Data were analysed using two-way analysis of variance (ANOVA). When a significant $F$-value was obtained $(P<$ $0.05)$, treatment means were compared using the Duncan's multiple range test. Data from the ECM colonisation were arcsin transformed and analysed without including the noninoculated control treatment. All statistical analyses were performed using the SPSS 17.0 software package (SPSS Inc., Chicago, IL, USA).

\section{Results}

\subsection{Experiment 1}

Growth substrate had a significant effect on shoot height, total plant dry weight and percentage of ECM colonisation, while fungal inoculation only had a significant effect on the percentage of ECM colonisation (Table 2). The interaction of both factors (growth substrate and fungal inoculation) only had a significant effect on shoot height. There were no significant differences in shoot height (Fig. 1a) and in total plant dry weight (Fig. 1b) between non-inoculated controls and plants inoculated with any of the tested ECM fungal isolates grown in both forest soil and in composted pine bark. However, plants grown in peat and inoculated with H. mesophaeum had a significantly greater shoot height and

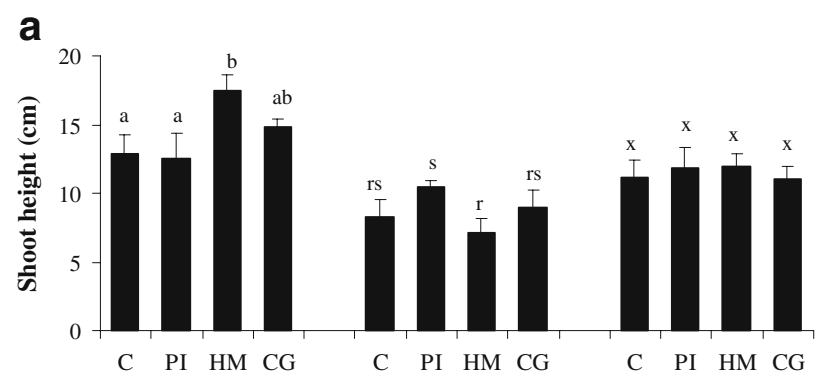

b
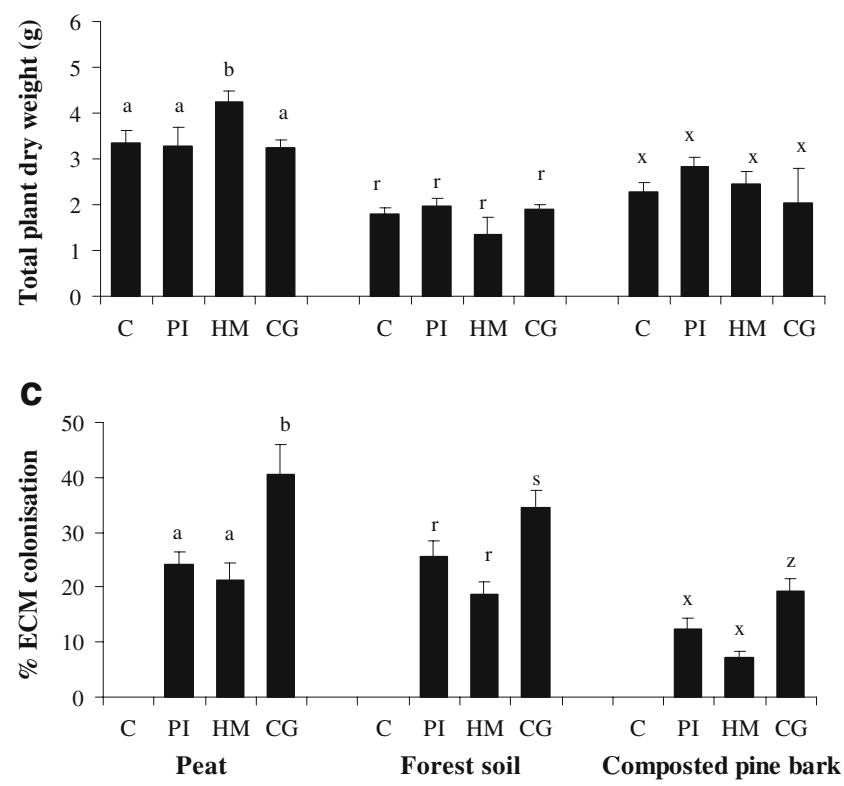

Fig. 1 Shoot height (a), total plant dry weight (b) and percentage of ectomycorrhizal colonisation (c) of Quercus ilex inoculated with Paxillus involutus (PI), Hebeloma mesophaeum (HM) and Cenococcum geophilum (CG) and non-inoculated control (C), grown on peat, forest soil and composted pine bark. Columns marked with different letters within each growth substrate differed significantly according to Duncan's multiple range test at $P<0.05$. Error bars are SEM. ECM, ectomycorrhizal 

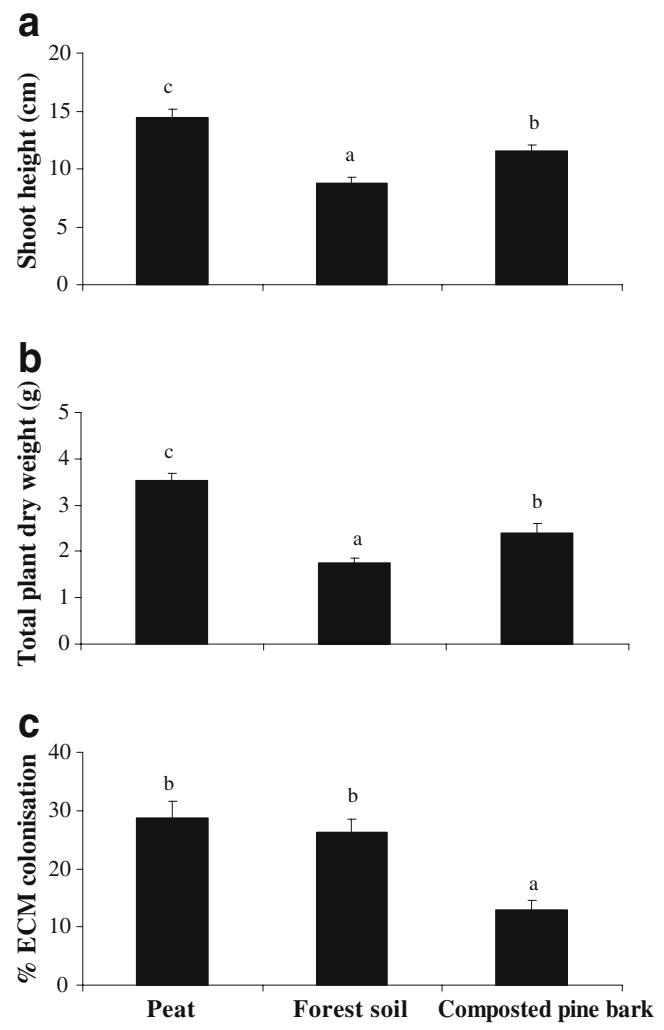

Fig. 2 Shoot height (a), total plant dry weight (b) and percentage of ectomycorrhizal colonisation (c) of Quercus ilex inoculated grown on peat, forest soil and composted pine bark. Columns marked with different letters differed significantly according to Duncan's multiple range test at $P<0.05$. Error bars are SEM. ECM, ectomycorrhizal

total plant dry weight when compared with non-inoculated controls.

There was no ECM colonisation in non-inoculated control plants in any of the growth substrates (Fig. 1c). Plants inoculated with C. geophilum had a significantly greater ECM colonisation than in any other inoculation treatment irrespective of growth substrate. Peat was the growth substrate in which $Q$. ilex had the greatest shoot height (Fig. 2a) as well as total plant dry weight (Fig. 2b) and this was statistically significant. The growth substrate on which the smaller shoot height and total plant dry weight were obtained was forest soil. Plants grown in peat and forest soil had a significantly greater percentage of ECM colonisation than those grown in composted pine bark (Fig. 2c). Overall, the best substrate for ECM colonisation and for plant growth was peat.

\subsection{Experiment 2}

Fertilisation only had a significant effect on the percentage of ECM colonisation, while fungal inoculation significantly influenced all measured parameters, except for leaf $\mathrm{N}$ concentration (Table 3). The interaction of both factors (growth substrate and fungal inoculation) had a significant effect on shoot height and leaf $\mathrm{P}$ concentration. Nonfertilised plants inoculated with $H$. mesophaeum had significantly greater shoot height when compared with plants from any other treatment (Fig. 3a). Significantly greater total plant dry weight was obtained in non-fertilised plants inoculated with H. mesophaeum when compared with non-inoculated control plants (Fig. 3b). There were no differences in leaf $\mathrm{N}$ concentration among all treatments. Non-fertilised plants inoculated with H. mesophaeum were the only ones where a significantly greater leaf $\mathrm{P}$ concentration was observed when compared with non-inoculated control plants (Fig. 3c).

There was no ECM colonisation in non-inoculated control plants irrespective of fertilisation regime (Fig. 3d). The greater percentage of ECM colonisation was obtained in plants inoculated with C. geophilum.

\section{Discussion}

Inoculation using ECM symbionts with a high mycorrhizal host-symbiont specificity and efficacy has the greatest potential for enhancing early establishment of tree seedlings at the nursery stage (Brundrett et al. 2005; Chen et al. 2006). Positive effects of artificial inoculation on seedlings under nursery conditions have been reported, particularly if tuning was performed prior to an application (Vosátka et al. 2008). The present study showed that $Q$. ilex seedlings exhibited positive growth response to inoculation with $H$. mesophaeum when cultivated on peat based compost. The seedling growth parameters used were those that are employed commercially to determine the value of seedlings

Table 3 Two-way ANOVA significances and $F$ values of the parameters measured in Experiment 2, according to fertilisation regime and fungal inoculation

\begin{tabular}{llllll}
\hline & Shoot height $(\mathrm{cm})$ & Total plant dry weight $(\mathrm{g})$ & Leaf P $\left(\mathrm{mg} \mathrm{g}^{-1}\right)$ & ${\text { Leaf N }\left(\mathrm{mg} \mathrm{g}^{-1}\right)}^{*} \%$ ECM colonisation \\
\hline Fertilisation (F) & $F=2.7 \mathrm{~ns}$ & $F=0.4 \mathrm{~ns}$ & $F=0.02 \mathrm{~ns}$ & $F=0.3 \mathrm{~ns}$ & $F=8.1 * *$ \\
Fungal inoculation (I) & $F=14.0 * * *$ & $F=9.1 * * *$ & $F=4.4 * *$ & $F=0.6 \mathrm{~ns}$ & $F=17.1 * * *$ \\
F x I & $F=4.3 *$ & $F=2.6 \mathrm{~ns}$ & $F=3.7 *$ & $F=0.5 \mathrm{~ns}$ & $F=0.01 \mathrm{~ns}$ \\
\hline
\end{tabular}

$*, * *, * * *$, significant effect at the level of $P<0.05, P<0.01$ and $P<0.001$, respectively; ns, non-significant effect; ECM, ectomycorrhizal 

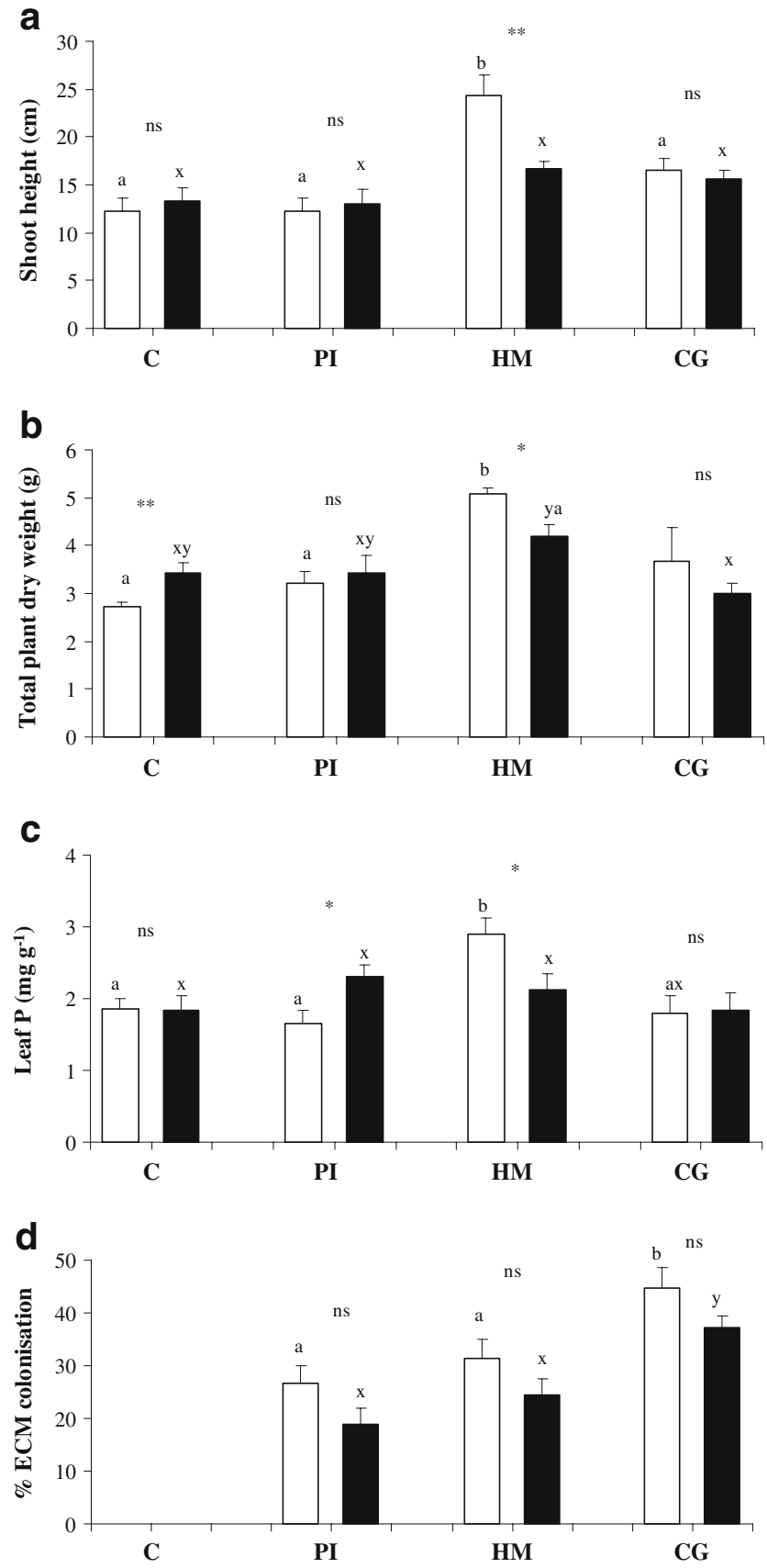

Fig. 3 Shoot height (a), total plant dry weight (b), leaf phosphorus concentration (c) and percentage of ectomycorrhizal colonisation (d) of Quercus ilex inoculated with Paxillus involutus (PI), Hebeloma mesophaeum (HM) and Cenococcum geophilum (CG) and non-inoculated control $(\mathrm{C})$, grown on peat with (black columns) and without (open columns) fertilisation. Columns marked with different letters within each fertilisation treatment differed significantly according to Duncan's multiple range test at $P<0.05$. Error bars are SEM. The effect of fertilisation within each inoculation treatment is noted by ns, $*$, ** (non-significant effect, significant effect at the level of $P<0.05$ and $P<0.01$, respectively). ECM, ectomycorrhizal and thus important for economic evaluation. Besides the assessed low percentages of ECM colonisation, significant effects on plant growth were obtained, showing that a high ECM colonisation is not always indicative of the inoculation success. The positive effect of ECM inoculation on plant growth, found in this study, may be due to enhanced nutrient uptake as well as induced phytohormone production in the plant, and/or the production of growth regulators and hormones by the ECM fungi. All these can positively change root physiology, growth, development and morphogenesis (Barker and Tagu 2000; Chalot et al. 2002; Luo et al. 2009).

Compared with forest soil and composted pine bark, the peat based compost was the superior growth substrate regardless of inoculation treatment. Composted pine bark was not suitable for growth or for mycorrhization possibly due to its higher pH (González-Ochoa et al. 2003) and/or the presence of phenolic compounds derived from the pine bark that can inhibit plant and fungal growth (Siqueira et al. 1991; Yun and Choi 2002).

The ultimate objective of ECM inoculation in nursery management is the production of higher quality nursery stock with improved field performance expressed as improved seedling survival, growth and wood quality. Under nursery conditions where plants are optimally irrigated and thus are seldom exposed to chronic environmental stress, the beneficial role of ECM symbiosis may be less evident (García et al. 2010). However, when plants are transplanted to the field they are much more exposed to various stresses and the full benefits of mycorrhiza can become evident (Baum et al. 2002; Perry et al. 1987; Quoreshi et al. 2008).

The most appropriate combination of substrate and ECM fungus for plant growth and nutrition was peat and $H$. mesophaeum. Only the inoculation with $H$. mesophaeum increased leaf $\mathrm{P}$ concentration. This shows not only the potential of mycorrhizas to facilitate $\mathrm{P}$ nutrition in $Q$. ilex plants but also that selection of appropriate ECM fungal symbiont is paramount to optimise the inoculation outcome. It seems that the presence of efficient ECM fungal symbionts is more important than actual content of $\mathrm{P}$ in the growing media. The major advantage of fertiliser use is that it speeds seedling production at the nursery phase. However, there are environmental consequences and economical disadvantages. Fertilisers can be an important fraction in production costs and a significant proportion of the applied fertiliser may be left in the soil, altering its microbial ecology. Furthermore, nutrients can be lost by leaching leading to eutrophication of nearby surface waters (Entry and Sojka 2007; Syers et al. 2008). Finally, fertilisers like pesticides or bare-root transplantation can reduce ECM colonisation on the roots of stock ready for final planting (Dell et al. 2002; Menkis et al. 2005). 
In this study plants inoculated with selected ECM fungi had a greater biomass than those given added fertiliser under nursery conditions. Reduction of agrochemical inputs is becoming vital in both forestry and agriculture. The results from this study show that it is possible to replace chemical fertilisers by ECM fungi in the nursery production of $Q$. ilex. In addition, the use of selected ECM fungi can be an effective and more environmental friendly approach to plant management in the nursery.

For optimising the production of $Q$. ilex, in the nursery, we recommend the use a peat-based substrate and inoculation of the seedlings with $H$. mesophaeum. This treatment can increase mycorrhizal colonisation and plant growth while reducing the need for fertiliser input. Current nursery practices do not guarantee sufficient mycorrhization of plant stock produced and plants without beneficial ECM symbionts can encounter shock after being transplanted to the field. This is particularly important when the targeted production of $Q$. ilex seedlings is for disturbed and/or arid ecosystems. The present study provides data that can help justify managerial decisions. If ECM inoculation is used, it can result in a decreased time to planting, less fertiliser input and more successful survival on out-planting, resulting in better quality $Q$. ilex nursery stock as well as reduced production costs.

Acknowledgements This work was supported by the EU program AGRO (DE\&D Action) Projecto AGRO 752, Medida 8-Desenvolvimento Tecnológico e Demonstração do Programa Operacional Agricultura e Desenvolvimento Rural. The authors wish to thank Fundação para a Ciência e a Tecnologia, POCI 2010 and FSE (III Quadro Comunitário de Apoio), Grant SFRH/BPD/23749/2005 for financial support. The authors thank Professor David Richardson for assistance with grammar and English and the anonymous reviewers for their helpful comments on the earlier draft of this manuscript.

Autoridade Florestal Nacional (2010) Inventário Florestal Nacional. http:// www.afn.min-agricultura.pt/portal/ifn. Accessed 31 May 2010

Barker SJ, Tagu D (2000) The roles of auxins and cytokinins in mycorrhizal symbioses. J Plant Growth Regul 19:144-154

Baum C, Stetter U, Makeschin F (2002) Growth response of Populus trichocarpa to inoculation by the ectomycorrhizal fungus Laccaria laccata in a pot and a field experiment. For Ecol Manag 163:1-8

Brundrett M, Bougher N, Dell B, Grove T, Malajczuk N (1996) Working with mycorrhizas in forestry and agriculture. ACIAR, Canberra

Brundrett M, Malajczuk N, Mingquin G, Daping X, Snelling S, Dell B (2005) Nursery inoculation of Eucalyptus seedlings in Western Australia and southern china using spores and mycelial inoculum of diverse ectomycorrhizal fungi from different climatic regions. For Ecol Manag 209:193-205

Chalot M, Javelle A, Blaudez D, Lambilliote R, Cooke R, Sentenac H, Wipf D, Botton B (2002) An update on nutrient transport processes in ectomycorrhizas. Plant Soil 244:165-175
Chen YL, Kang LH, Malajczuk N, Dell B (2006) Selecting ectomycorrhizal fungi for inoculating plantations in south China: effect of Scleroderma on colonization and growth of exotic Eucalyptus globulus, E. urophylla, Pinus elliottii, and P. radiata. Mycorrhiza 16:251-259

Dell B, Malajczuk N, Dunstan WA (2002) Persistence of some Australian Pisolithus species introduced into eucalypt plantations in China. For Ecol Manag 169:271-281

Domínguez JA, Selva J, Rodríguez Barreal JA, Saiz de Omeñaca JA (2006) The influence of mycorrhization with Tuber melanosporum in the afforestation of a Mediterranean site with Quercus ilex and Quercus faginea. For Ecol Manag 231:226-233

Entry JA, Sojka RE (2007) Matrix based fertilizers reduce nitrogen and phosphorus leaching in three soils. J Environ Manag 87:364-372

Garbaye J (2000) The role of ectomycorrhizal symbiosis in the resistance of forest to water stress. Outlook Agric 29:63-69

García AN, Árias SPB, Morte A, Sánchez-Blanco MJ (2010) Effects of nursery preconditioning through mycorrhizal inoculation and drought in Arbutus unedo L. plants. Mycorrhiza doi:10.1007/ s00572-010-0310-x

González-Ochoa AI, Heras J, Torres P, Sánchez-Gómez E (2003) Mycorrhization of Pinus halepensis Mill. and Pinus pinaster Aiton seedlings in two commercial nurseries. Ann For Sci 60:43-48

Hall JL (2002) Cellular mechanisms for heavy metal detoxification and tolerance. J Exp Bot 53:1-11

Khasa PD, Sigler L, Chakravarty P, Dancik BP, Erikson L, Mc Curdy D (2001) Effect of fertilization on growth and ectomycorrhizal development of container-grown and bare-root nursery conifer seedlings. New For 22:179-197

Liu Q, Loganathan P, Hedley MJ, Grace LJ (2008) Effect of mycorrhizal inoculation on rhizosphere properties, phosphorus uptake and growth of pine seedlings treated with and without a phosphate rock fertilizer. J Plant Nutr 31:137-156

Luo ZB, Janz D, Jiang X, Göbel C, Wildhagen H, Tan Y, Rennenberg H, Feussner I, Polle A (2009) Upgrading root physiology for stress tolerance by ectomycorrhizas: insights from metabolite and transcriptional profiling into reprogramming for stress anticipation. Plant Physiol 151:1902-1917

Marx DH (1969) The influence of ectotrophic mycorrhizal fungi on the resistance of pine roots to pathogenic infections. I. Antagonism of mycorrhizal fungi to root pathogenic fungi and soil bacteria. Phytopathology 59:153-163

Menkis A, Vasiliauskas R, Taylor AFS, Stenlid J, Finlay R (2005) Fungal communities in mycorrhizal roots of conifer seedlings in forest nurseries under different cultivation systems, assessed by morphotyping, direct sequencing and mycelial isolation. Mycorrhiza $16: 33-41$

Novozamsky I, Houba VJG, Van Eck R, Van Vark W (1983) A novel digestion technique for multi-element plant analysis. Commun Soil Sci Plant Anal 14:239-248

Perry AD, Molina R, Amaranthus PM (1987) Mycorrhizae, mycorrhizospheres, and reforestation: current knowledge and research needs. Can J For Res 17:929-940

Quoreshi AM, Piché Y, Khasa DP (2008) Field performance of conifer and hardwood species 5 years after nursery inoculation in the Canadian Prairie Provinces. New For 35:235-253

Richard F, Millot S, Gardes M, Selosse M-A (2005) Diversity and specificity of ectomycorrhizal fungi retrieved from an old-growth Mediterranean forest dominated by Quercus ilex. New Phytol 166:1011-1023

Rincón A, Parlade J, Pera J (2007) Influence of the fertilisation method in controlled ectomycorrhizal inoculation of two Mediterranean pines. Ann For Sci 64:577-583

Rivero SHT, Moorillón VGN, Borunda EO (2009) Growth, yield, and nutrient status of pecans fertilized with biosolids and inoculated with rizosphere fungi. Bioresour Technol 100:1992-1998 
Scarascia-Mugnozza G, Oswald H, Piussi P, Radoglou K (2000) Forests of the Mediterranean region: gaps in knowledge and research needs. For Ecol Manag 132:97-109

Siqueira JO, Nair MG, Hammerschmidt R, Safir GR, Putnam AR (1991) Significance of phenolic compounds in plant-soil microbial systems. Critic Rev Plant Sci 10:63-121

Smith SE, Read DJ (2008) Mycorrhizal symbiosis, 3rd edn. Academic, London

Syers JK, Johnston AE, Curtin D (2008) Efficiency of soil and fertilizer phosphorus use. Reconciling changing concept of soil phosphorus behaviour with agronomic information. FAO fertilizer and plant nutrition bulletin, 18. Rome

Vaario L, Tervonen A, Haukioja K, Haukioja M, Pennanen T, Timonen S (2009) The effect of nursery substrate and fertilization on the growth and ectomycorrhizal status of containerized and outplanted seedlings of Picea abies. Can J For Res 39:64-75

Vosátka M, Gajdoš J, Kolomý P, Kavková M, Oliveira RS, Franco AR, Sousa NR, Carvalho MF, Castro PML, Albrechtová J (2008) Applications of ectomycorrhizal inocula in nursery and field plantings: the importance of inoculum tuning to target conditions. In: Feldmann F, Kapulnik Y, Baar J (eds) Mycorrhiza works. German Phytomedical Society, Braunschweig, pp 112-125

Walinga I, Van Vark W, Houba VJG, van der Lee JJ (1989) Plant analysis procedures (soil and plant analysis, Part 7). Syllabus, Wageningen

Yun KW, Choi SK (2002) Mycorrhizal colonization and plant growth affected by aqueous extract of Artemisia princeps var. orientalis and two phenolic compounds. J Chem Ecol 28:353-362 